\title{
Amplitudes, rates, periodicities and causes of temperature variations in the past 2485 years and future trends over the central-eastern Tibetan Plateau
}

\author{
LIU Yu ${ }^{1,2^{*}}$, CAI QiuFang ${ }^{1}$, SONG HuiMing ${ }^{1,3}$, AN ZhiSheng ${ }^{1} \&$ Hans W. LINDERHOLM ${ }^{4}$ \\ ${ }^{1}$ The State Key Laboratory of Loess and Quaternary Geology, Institute of Earth Environment, Chinese Academy of Sciences, Xi'an 710075, \\ China; \\ ${ }^{2}$ Department of Environmental Science and Technology, School of Human Settlements and Civil Engineering, Xi'an Jiaotong University, Xi'an \\ 710049, China; \\ ${ }^{3}$ Graduate University of Chinese Academy of Sciences, Beijing 100049, China; \\ ${ }^{4}$ Regional Climate Group, Department of Earth Sciences, University of Gothenburg, SE-40530 Gothenburg, Sweden
}

Received March 8, 2011; accepted July 14, 2011

\begin{abstract}
Amplitudes, rates, periodicities, causes and future trends of temperature variations based on tree rings for the past 2485 years on the central-eastern Tibetan Plateau were analyzed. The results showed that extreme climatic events on the Plateau, such as the Medieval Warm Period, Little Ice Age and 20th Century Warming appeared synchronously with those in other places worldwide. The largest amplitude and rate of temperature change occurred during the Eastern Jin Event (343-425 AD), and not in the late 20th century. There were significant cycles of 1324 a, 800 a, 199 a, 110 a and 2-3 a in the 2485-year temperature series. The 1324 a, 800 a, 199 a and 110 a cycles are associated with solar activity, which greatly affects the Earth surface temperature. The long-term trends (>1000 a) of temperature were controlled by the millennium-scale cycle, and amplitudes were dominated by multi-century cycles. Moreover, cold intervals corresponded to sunspot minimums. The prediction indicated that the temperature will decrease in the future until to $2068 \mathrm{AD}$ and then increase again.
\end{abstract}

central-eastern Tibetan Plateau, temperature, amplitude, rate, periodicity, cause, future trend

Citation: $\quad$ Liu Y, Cai Q F, Song H M, et al. Amplitudes, rates, periodicities and causes of temperature variations in the past 2485 years and future trends over the central-eastern Tibetan Plateau. Chinese Sci Bull, 2011, 56: 2986-2994, doi: 10.1007/s11434-011-4713-7

Within the research field of global change, there is currently great interest in long-term temperature variation characteristics, such as the amplitude, rate of change, periodicity, and cause of past and future trends of temperature, at global and regional scales. Many aspects of the climate over the past 2000 years remain unclear; e.g. the temperature amplitude changes from a cold phase to warm phase, the warming rate during warm periods, variation periodicities, causes of variations, and whether the 20th century was the warmest in the past 1000 or 2000 years.

The Earth's climate is complex and sensitive to solar activity $[1,2]$. Solar activity has millennium and multi-century

*Corresponding author (email: liuyu @ loess.llqg.ac.cn)
(200 a and 100 a) variation cycles [1,2]. Among them, millennium-scale cycles are important and have been identified in numerous geological records since the Holocene [3], and can even be traced back $400 \mathrm{ka}$ [4]. Since the millenniumscale cycle is one of the dominant cycles of climate change and has persisted for such a long time, there is no known reason why it should be interrupted in our time.

To better understand climate change as a natural process in the past 2000 years, the proxy used should not only have high (annual) resolution but also contain two complete long-term cycles [5]. Unfortunately, there are few temperature series meeting these two conditions. The millennial cycle has not been recognized widely so far in climate research on the last 2000 years, mainly because the lengths of 
temperature series are limited. This reduces the accuracy in predicting future climate trends.

Records used in studying climate during the past 2000 years are ice cores [6], corals [7], speleothems [8,9], lacustrine deposits [10], historical documents [11,12] and tree rings [13]. Tree rings play an important role in the study of climate change, especially for the climate of the past 2000 years, because of their precise dating, high resolution and continuous recording. They serve as major data sources for reconstructing regional, hemispherical and global temperatures during the past 1000 to 2000 years [14].

Although tree-ring records are widely available, treering-based reconstructions are mostly shorter than 1000 years, with few reaching 2000 years, which greatly limits the recognizing of characteristics of climate change on the millennial scale. A temperature series for the past 2485 years for the central-eastern Tibetan Plateau [13] provide a unique opportunity to study climate variation on the millennium scale. In this paper, climate characteristics such as amplitudes, rates, and periodicities are discussed on the basis of the 2485-year temperature series, and the possible mechanism of temperature variation is explored preliminarily. Finally, future variation trends are predicted.

\section{Materials and methods}

The 2485-year temperature data used in this study are taken from reference [13]. This temperature series is not only representative of the central-eastern Tibetan Plateau, but also the vast area of central-northern China. It is also significantly correlated with seven other temperature series of the Northern Hemisphere [13]. It even has a teleconnection with series for middle-low latitudes in the Southern Hemisphere [15]. Therefore, the spatial representative of this temperature series is quite clear. Since a conservative negative exponential or linear regression is employed in the detrending process, most low-frequency signals are preserved in the chronology and can be used to detect the low-frequency components of climate change.

The methods employed in this paper are as follows. (1) Cold and warm periods are defined as those for which the temperature is respectively half a standard deviation below and above the mean temperature for the 2485 years. (2) The amplitude is defined as the difference in the mean temperature between two adjacent cold and warm periods. (3) The rate is defined as the slope of a trend line for a certain period of increasing or decreasing temperature. (4) Redfit 35 software was employed to detect periodicities of the 2485year temperature series. The parameters set for this analysis were $n 50=4$ (WOSA segment: Welch Overlap Segment Averaging procedure) and iwin $=2$ (a Hanning smoothing window was selected). Other parameters were default settings [16]. (5) The Caterpillar-SSA [17] method was employed to predict future temperature trends for the next 120 years on the Tibetan Plateau; for details, see reference [18]. There are four steps to the analysis: embedding, singular-value decomposition, grouping and diagonal averaging. The sole and important parameter of the embedding step is the maximum time lag $L$, also referred to as the window length. In this paper, we choose 1700 years as the window length $(L)$ for the temperature series because it relates closely to the 1324-year cycle. The Caterpillar-SSA method can identify fluctuations with cycles at $L / 15-L$. We employed the Ward method and Euclidean distance in cluster analysis. The process was spread using a tree diagram. A recurrent method was applied for prediction.

\section{Results and discussions}

\subsection{Amplitudes, variabilities and rates of change in the 2485-year temperature series}

(1) Amplitude of temperature variation. This paper mainly deals with the characteristics of temperature variations on millennial to centurial scales, and the interannual and decadal scales of temperature change are neglected. Thus, the mean temperature and standard deviation were calculated for the entire 2485-year temperature series.

Calculation results show that the mean annual temperature for the period from $484 \mathrm{BC}$ to $2000 \mathrm{AD}$ on the central-eastern Tibetan Plateau was $2.12^{\circ} \mathrm{C}$ and the standard deviation was $0.40^{\circ} \mathrm{C}$. Therefore, six cold and six warm periods were identified in the whole series (Table 1). This result is more accurate and quantitative than that in [13].

During the past 2485 years, the temperature amplitude was a maximum during the East Jin Event (EJE) [13]. The EJE had two stages, with the temperature decreasing in the first (C2) and then increasing in the later (W2). The mean temperature suddenly increased from $1.66^{\circ} \mathrm{C}(\mathrm{C} 2)$ to $2.67^{\circ} \mathrm{C}$ (W2, Table 1), while the temperature amplitude reached $1.01{ }^{\circ} \mathrm{C}$ within 30 years. The mean temperature during $\mathrm{C} 2$ was even lower than that of the Little Ice Age (LIA). The coldest years in $\mathrm{C} 2$ (with a mean temperature of $1.38^{\circ} \mathrm{C}$ ) were 362-369 $\mathrm{AD}$ and the temperature was about $1.5^{\circ} \mathrm{C}$ lower than the mean temperature for the late 20th century. The coldest event captured in the tree-ring record was also described in historical documents: "It had been extremely cold for three years starting from $366 \mathrm{AD}$, while the sea water was totally frozen from Changli to Yingkou along the Bohai gulf. Thousands of military soldiers and gharries could come and go across the Bohai gulf on the ice" [19].

The 2485-year temperature curve, along with others for the Northern Hemisphere [20-22], exhibited a gradually increasing trend since the LIA. The amplitude of temperature change from $\mathrm{C} 6$ to $\mathrm{W} 6$ was $0.79^{\circ} \mathrm{C}$. If we only focus on the 20th century, the amplitude from 1911-1920 AD to 1991-2000 AD was also $0.79^{\circ} \mathrm{C}$. These two values are very close to the increase in the Earth surface temperature $\left(0.74^{\circ} \mathrm{C}\right)$ during the last 100 years, evaluated by IPCC4 [23], 
Table 1 Amplitudes and rates during cold and warm intervals on the central-eastern Tibetan Plateau for the past 2485 years ${ }^{\text {a) }}$

\begin{tabular}{|c|c|c|c|c|}
\hline Cold $(\mathrm{C}) /$ Warm $(\mathrm{W})$ period & Interval & Mean temperature $\left({ }^{\circ} \mathrm{C}\right)$ & Amplitude $\left({ }^{\circ} \mathrm{C}\right)$ & Rate $\left({ }^{\circ} \mathrm{C} / 10 \mathrm{a}\right)$ \\
\hline $\mathrm{C} 1$ & $-437--412$ & 1.64 & \multirow[b]{2}{*}{$\mathrm{W} 1-\mathrm{C} 1=0.71$} & \multirow[b]{2}{*}{0.03} \\
\hline W1 & $-266--235$ & 2.35 & & \\
\hline $\mathrm{C} 2$ & $343-367$ & 1.66 & $\mathrm{C} 2-\mathrm{W} 1=-0.70$ & -0.003 \\
\hline W2 & $388-425$ & 2.67 & $\mathrm{~W} 2-\mathrm{C} 2=1.01$ & 0.77 \\
\hline $\mathrm{C} 3$ & $460-485$ & 1.83 & $\mathrm{C} 3-\mathrm{W} 2=-0.84$ & -0.17 \\
\hline W3 & $585-640$ & 2.44 & W3-C3=0.61 & 0.04 \\
\hline $\mathrm{C} 4$ & $682-714$ & 1.72 & \multirow{2}{*}{$\mathrm{C} 4-\mathrm{W} 3=-0.72$} & \multirow{2}{*}{-0.08} \\
\hline W4 & $784-900$ & 2.5 & & \\
\hline W5 & $942-1014$ & 2.5 & W4-C4=0.78 & 0.05 \\
\hline $\mathrm{C} 5$ & $1268-1306$ & 1.83 & C5-W5 $=-0.67$ & -0.01 \\
\hline C6 & $1595-1713$ & 1.78 & W6-C6=0.79 & 0.02 \\
\hline \multirow[t]{3}{*}{ W6 } & 1960-2000 & 2.57 & & \\
\hline & $1911-1920$ & 2.07 & & \\
\hline & 1990-2000 & 2.86 & 0.79 & \\
\hline
\end{tabular}

a) Positive values: from a cold period to warm period; negative values: from a warm period to cold period.

indicating that the increasing rate of temperature on the Tibetan Plateau has been stable since the 17th century, and the temperature has increased synchronously with the global temperature. The amplitude on the plateau in the 20th century was slightly higher $\left(0.05^{\circ} \mathrm{C}\right)$ than that on a global scale. However, the amplitude of temperature in the 20th century $\left(0.79^{\circ} \mathrm{C}\right)$ was much lower than that of the EJE $\left(1.01^{\circ} \mathrm{C}\right)$ on the Plateau.

There were two warm periods, W4 and W5, during 7841014 AD, most likely corresponding to Zhu's result [19] that there was a warming interval during 600-1000 AD in the Sui and Tang dynasties. It seemed that the duration of the Medieval Warm Period (MWP) was earlier in China than in the Western Hemisphere [24]. However, at almost the same time as a warm period during 900-1000 AD observed in the GISP $2 \delta^{18} \mathrm{O}$ records of an Greenland ice core [25], W5 occurred on the Tibetan Plateau. This suggested that the MWP existed worldwide or at least synchronously at the high elevations of western China and high latitudes of the Northern Hemisphere. It should also be noted that the longest cold period was 1595-1713 AD, which was homochronous with the worldwide LIA maximum [26].

The mean temperature of the late EJE $\left(2.67^{\circ} \mathrm{C}\right)$ was the highest in the 2485 years, even exceeding that of the second half of the 20 th century $\left(2.57^{\circ} \mathrm{C}\right)$. In other words, the late 20 th century was not the warmest period in history. The $\delta^{18} \mathrm{O}$ record of Jinchuan peat revealed that the degree of warming around $420 \mathrm{AD}$ was not inferior to that of other warm periods in the past 6000 years [27], and this warm event coincided almost exactly with the highest peak around $413 \mathrm{AD}$ in the 2485 years for the Tibet Plateau. This is further evidence of the EJE existing over the large scale of China.

(2) Temperature variability. We defined temperature variability as the standard deviation of the 40-year moving average. Figure 1 shows that the temperature variability was greater in warm periods, such as W2 and W6. In fact, the mean temperature gradually increased for 600 years after the EJE, and accordingly, the variability obviously increased. On the contrary, in cold periods, such as 682-714 $\mathrm{AD}$ and 1595-1713 AD, the temperature variability was comparatively low and the amplitude of temperature change was small. It is thus concluded that the temperature variability was comparatively large with strong fluctuation of the interannual temperature in warm intervals and small with weak fluctuations in cold intervals.

(3) Rate of temperature variation. We calculated rates of temperature variation in 10-year intervals and found that the rate of temperature variation was highest in 362-390 AD (C2-W2) with a value $0.77^{\circ} \mathrm{C} / 10$ a. The next highest rate $\left(0.35^{\circ} \mathrm{C} / 10\right.$ a) was for the period $881-908$ AD between $\mathrm{W} 4$ and $\mathrm{W} 5$. There were low rates of variation in two long-term intervals: $0^{\circ} \mathrm{C} / 10 \mathrm{a}$ in $228 \mathrm{BC}-362 \mathrm{AD}$ and $0.01^{\circ} \mathrm{C} / 10 \mathrm{a}$ in 1271-1545 AD. There was an apparent warming trend in the 20th century on the Plateau, with a rate of $0.11^{\circ} \mathrm{C} / 10$ a during 1918-2000 AD; this is similar to what IPCC4 reported $\left(0.13^{\circ} \mathrm{C} / 10 \mathrm{a}\right)$ for the past 50 years [23]. These two values are higher than the global average rate $\left(0.044^{\circ} \mathrm{C} / 10 \mathrm{a}\right)$ during 1850-2008 AD [28]. In general, the calculations showed that the warming rate in the 20th century was not the highest in the past 2485 years.

\subsection{Periodicity of temperature variation}

Power spectrum analysis reveals that the major periodicities were concentrated on 1324 a, 800 a, 199 a, 110 a and 2-3 a at the $99 \%$ confidence level and 66 a and 38 a at the $95 \%$ level in the 2485-year temperature series (Figure 2). The 


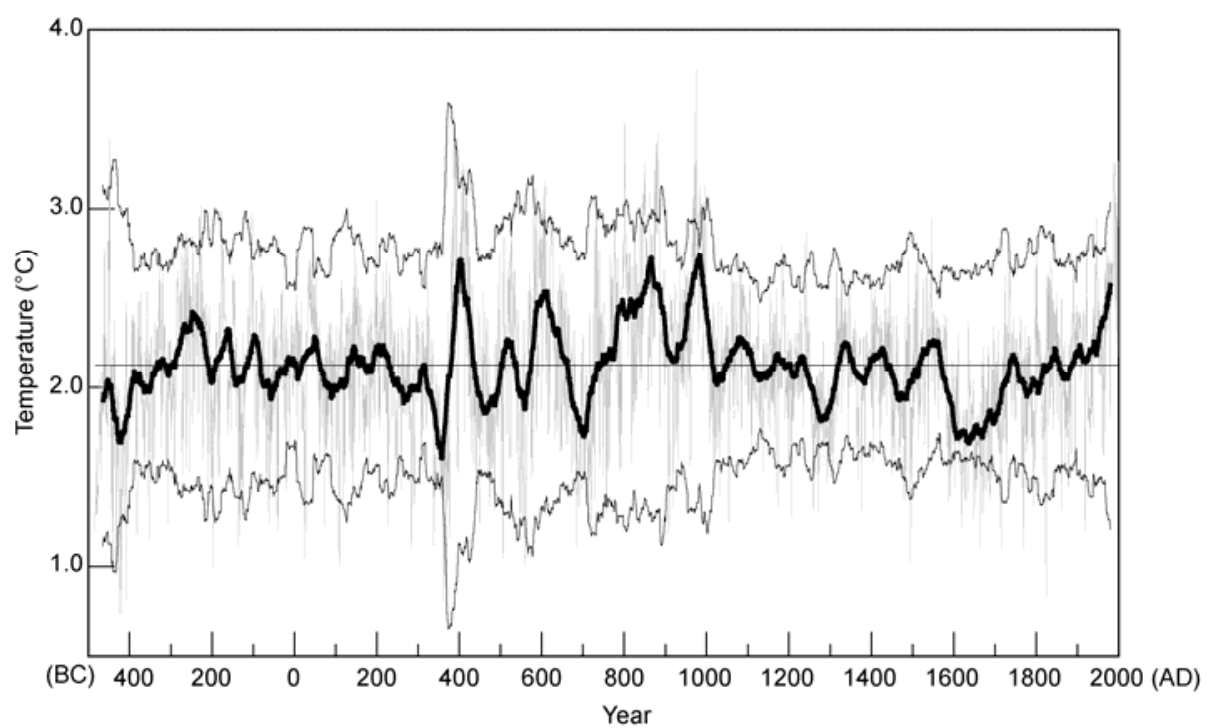

Figure 1 Tree-ring-based temperature reconstruction for the central-eastern Tibetan Plateau during the past 2485 years (gray line), the 40-year moving average (thick black line) and the 40-year running standard deviation (thin black line); the horizontal line is the mean temperature for the 2485 years.

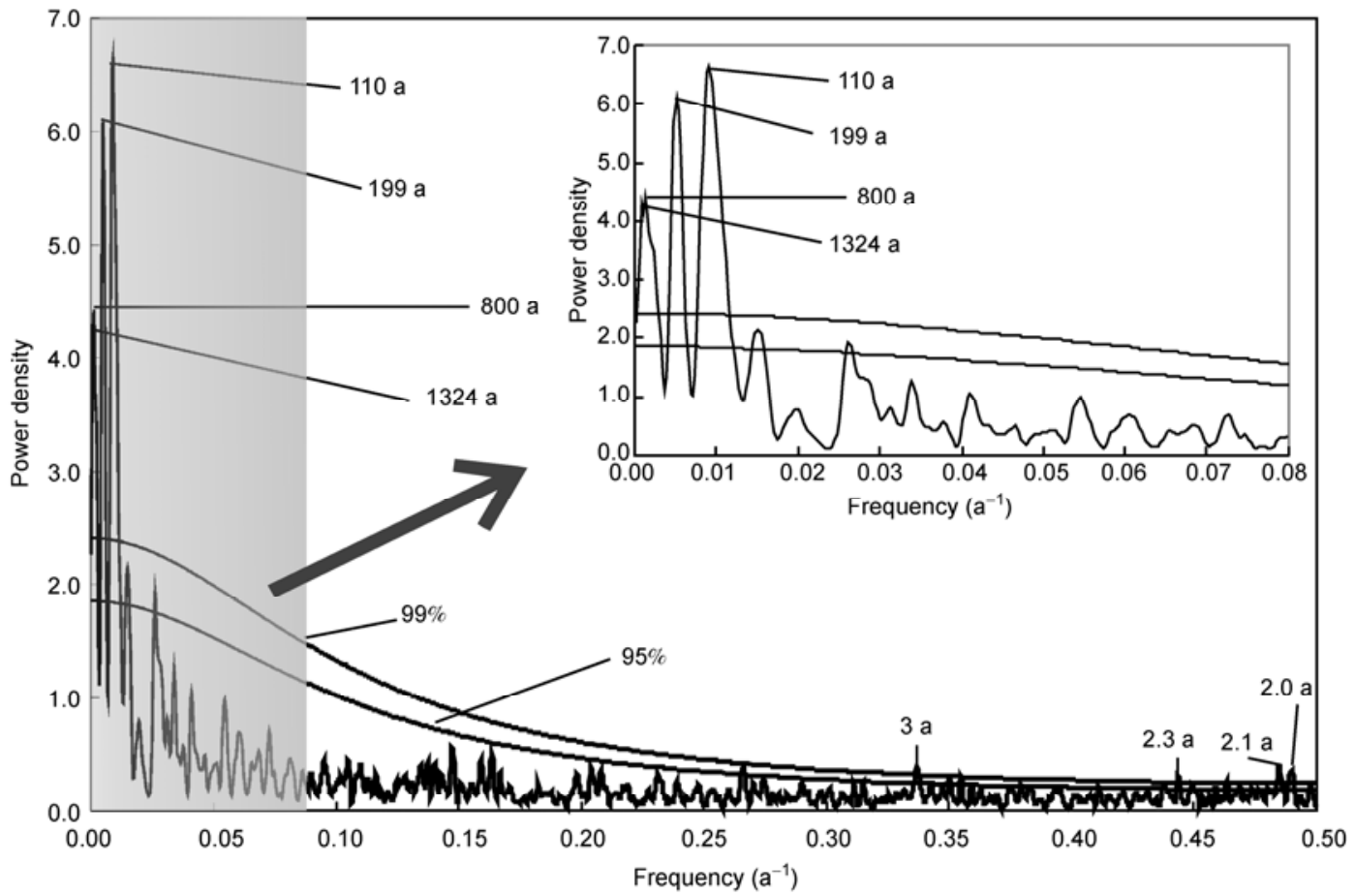

Figure 2 Power spectrum analysis of the 2485-year temperature series.

2-3 a cycles existed widely [29-34] and were attributed to quasi-biennial oscillation (QBO). The QBO is speculated to be an important characteristic of atmospheric circulation and climate change [35]. The 38 a cycle is close to the Bruckner cycle [36], and the 66 a cycle is regarded as a global-climate-system cycle [37]. Whether the 800 a cycle can be attributed to the 1000 a cycle is currently unclear. In this paper, we only focus on the cycles of 1324 a, 199 a and $110 \mathrm{a}$.

(1) Millennium-scale cycle. The 1324 a cycle is notable in Figure 2 and approximates the well-known dominant climate-change cycles $1374 \pm 502$ a in the Holocene [3] and the 1470 a cycle in Dansgaard/Oeschger (D-O) events in the last glacial period. All these cycles are referred to as millennium-scale cycles. The 2485-year temperature series can be divided into four stages: in stage I (250 BC-369 AD), the temperature gradually decreased for about 600 years; in stage II (370-999 AD), the temperature gradually increased for nearly 600 years; in stage III (1000-1600 AD), the temperature decreased for 600 years; and in stage IV 
(1601-2000 AD), the temperature has increased step by step for about 400 years until the present. The entire series from stage I to IV looks like a sawtooth wave (Figure 3). Stage I and II are a complete millennium-scale cycle, and stage I to III are one-and-a-half millennium-scale cycles.

The global climatic system is greatly affected by the millennium-scale cycles. There has been much geological evidence of millennium-scale cycles, from North America to Europe and from the Middle East to East Asia. A 1500 a cycle was found in deep-sea sediment records for the North Atlantic [3], lake sediment records for Alaska [1], pollen records for the Ptolemais basin, Greece [38], loess records for Jiuzhoutai, China [39] and sea surface temperature records for the North Pacific at mid-latitudes [40]. 1450 and 1150 a cycles were detected for the $74 \mathrm{~K} 1$ hole in the Arabian Sea [41]. There was a 1200 a cycle in Eurasian climate history [42]. In China, a 1463 a cycle was found in Zoige peat records [43], a 1140 a cycle in sediment records of lake Huguang Maar since the Holocence [44], and 1087-1220 a cycles in a temperature series for Hongyuan [27].

There is evidence worldwide indicating that millennium-scale cycles are the dominant factors for climatic fluctuation during the Holocene, and the exact periodicity of the millennium-scale cycle was modified as $1374 \pm 502$ a by Bond et al. [3]. The inducement mechanism of these cycles may be associated with solar activity $[3,42,45]$, and perhaps, the inherent solar cycle $[2,46]$.

This moderate millennium-scale cycle has lasted for such a long time that there is no reason for it to disappear in the last 2000 years. However, it has been mentioned rarely in the study of the climate in the last 2000 years; a possible reason is that reported temperature series have not been long enough.

There are alternating cold and warm intervals in the 2485-year temperature curve: 600-year increases and 600 -year decreases. This regularity of climate change is expected to continue. There were turning points from a cold interval to a warm interval at 343-367 AD (the EJE) and 1595-1713 AD (the LIA). Likewise, the MWP is the turning point from a warm to cold phase under the control of the millennium-scale cycle.

(2) Multi-century-scale cycles. The significant multicentury-scale cycles were 199 a and 110 a in the 2485-year temperature series for the central-eastern Tibetan Plateau.
They are close to the quasi-200 a (Suess cycle or de Vries cycle) [45] and quasi-70 a-100 a cycle (Gleissberg cycle) $[46,47]$ of solar activity, respectively, which have been found in extensive geological records [34,48-59]. Quasi200 a and quasi-100 a cycles are extremely notable in research on the global temperature in the last millennium.

Multi-century cycles related to solar activity strongly affect the Earth's climate system. They have left footprints in various geobiological carriers. Thus, it is not surprising to detect these two century-scale cycles in the Tibetan temperature curve.

\subsection{Causes of warm periods}

It has been reported that global warming in the late 20th century has resulted from the constructive overlapping of multiple cycles ( 21 a, 64 a and 179 a) commonly in uplift phases [60]. However, in our opinion, in addition to the cycles above, millennium-scale cycles have also made a great contribution to the warming, as well as to other warming periods historically.

Among the significant cycles in the 2485-year temperature series, two century-scale cycles (199 a and 110 a) have dominantly affected the amplitude of the temperature variations. The 110 a cycle (with largest amplitude $A=1.875^{\circ} \mathrm{C}$ ) contributed more than the 199 a cycle (with largest amplitude $A=1.399^{\circ} \mathrm{C}$ ) to the amplitude of temperature variations.

If the two century-scale cycles are in ascending phases while the millennium-scale cycle is near its peak, then the constructive overlapping of these three cycles could produce a warm period. If we take the warm periods from W1 to W6 as examples (Figure 4), they all corresponded to the constructive overlapping of 1324 a, 199 a and 110 a cycles. There were extremely cold periods when the 119 a and 110 a cycles were in their declining stages and the 1324 a cycle was near its minimum; e.g. the EJE and LIA.

The millennium-scale cycle regulated the century-scale cycles and controlled the long-term trend of temperature change, although its maximum amplitude $A$ was only $0.848^{\circ} \mathrm{C}$. If the millennial cycle was in a declining phase, there was no warm period irrespective of how strongly the century cycles uplifted; e.g. stage I (250 BC-369 AD) and stage III (1000-1600 AD) (Figure 3). On the other hand, in

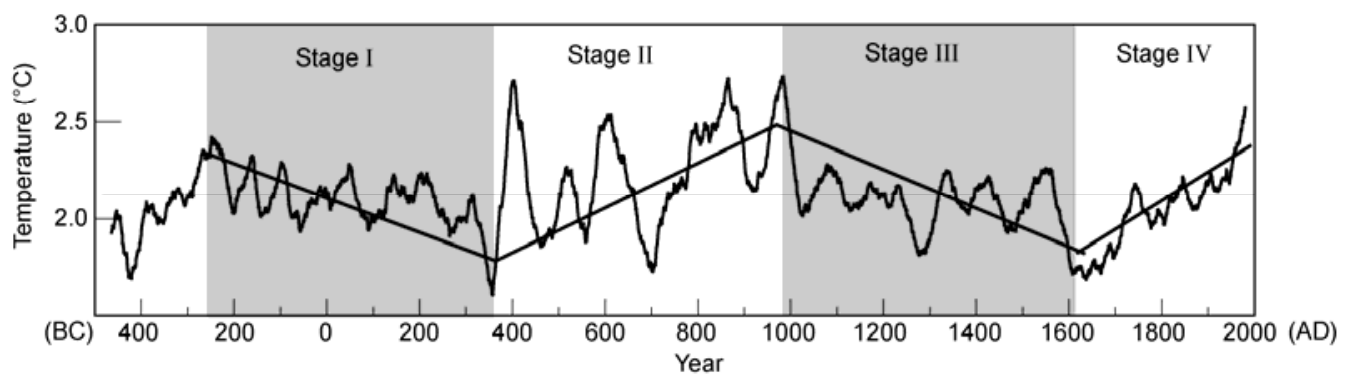

Figure 3 Millennium-scale cycle in the temperature variation during the last 2485 years. 


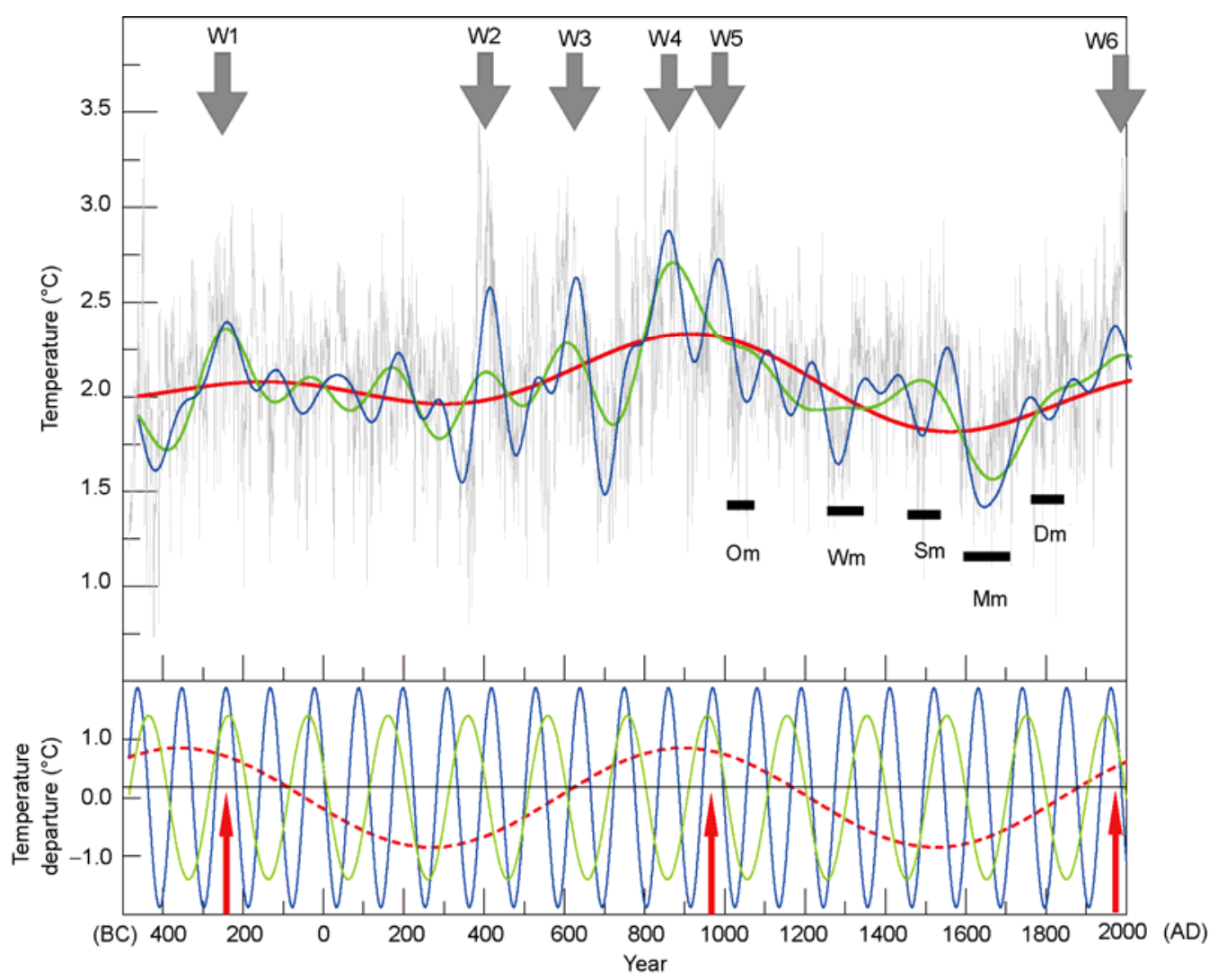

Figure 4 Decomposition of the main cycles of the 2485-year temperature series on the Tibetan Plateau and periodic function simulation. Top: Gray line, original series; red line, 1324 a cycle; green line, 199 a cycle; blue line, 110 a cycle. Bottom: Three sine functions for different timescales. 1324 a, red dashed line $(y=0.848 \sin (0.005 t+0.23)) ; 199 \mathrm{a}$, green line $(y=1.40 \sin (0.032 t-0.369)) ; 110 \mathrm{a}$, blue line $(y=1.875 \sin (0.057 t+2.846))$; time $t$ is the year from $484 \mathrm{BC}$ to $2000 \mathrm{AD}$.

stage II (370-999 AD) and stage IV (1601-2000 AD), when the millennial cycle was in a rising phase, the warm trend was still increasing no matter that the century-scale cycles were declining during some intervals.

Figure 4 (bottom) shows the simulation results using three sine functions for the period $484 \mathrm{BC}-2000 \mathrm{AD}$. Three sine functions have periods of $1324 \mathrm{a}, 199 \mathrm{a}$ and $110 \mathrm{a}$. Again, it was observed that if the two century-scale cycles were in ascending phases while the millennium-scale cycle was near its peak, the constructive overlapping of these three cycles produced a warm period (Figure 4, bottom, red arrows). Other warm and cold intervals were also simulated using the three functions.

It is interesting to note that sunspot minimums correspond to the cold periods in the 2485-year temperature series well. For example, the cold period of 1015-1040 AD corresponds to the Oort minimum (Om, 1010-1080 AD), the cold period of 1258-1309 AD (C5) to the Wolf minimum (Wm, 1270-1350 AD), the cold period of 1451-1539 $\mathrm{AD}$ to the Spörer minimum (Sm, 1430-1520 AD), the cold period of 1620-1715 AD (C6) to the Maunder minimum (Mm, 1620-1710 AD) and the cold period of 1766-1824 $\mathrm{AD}$ to the Dalton minimum (Dm, 1787-1843 AD) [61] (Figure 4, top).

A previous study [13] stated that the low-frequency component of the 2485-year temperature curve was quite similar to that of the solar radiation curve. Further study in this paper revealed that the solar activity was a major driving factor of the climate variations on the central-eastern Tibetan Plateau, or in an even larger region. The millennial cycle of solar activity determined the long-term trends ( $>1000$ a) of temperature variations; meanwhile, the centurial cycles determined the amplitude of the temperature variations. It is also worth noting that almost all sunspot minimums corresponded to low-temperature intervals. However, the interannual- to decadal-scale temperature changes might be related to atmospheric circulations. This followed a comment made by Zhu [19]: "The large changes of the Earth's climate have been controlled by solar radiation, but the small changes by atmospheric circulations".

\subsection{Prediction of temperature trends in the next $\mathbf{1 2 0}$ years}

We believe that the periodic oscillations are natural process in the climate system, which have existed for thousands of years, and will continue in the coming hundreds of years. This is a theoretical base for climate prediction. Caterpillar-SSA is a novel and powerful method for time series analysis and forecasting. It has been successfully applied to 


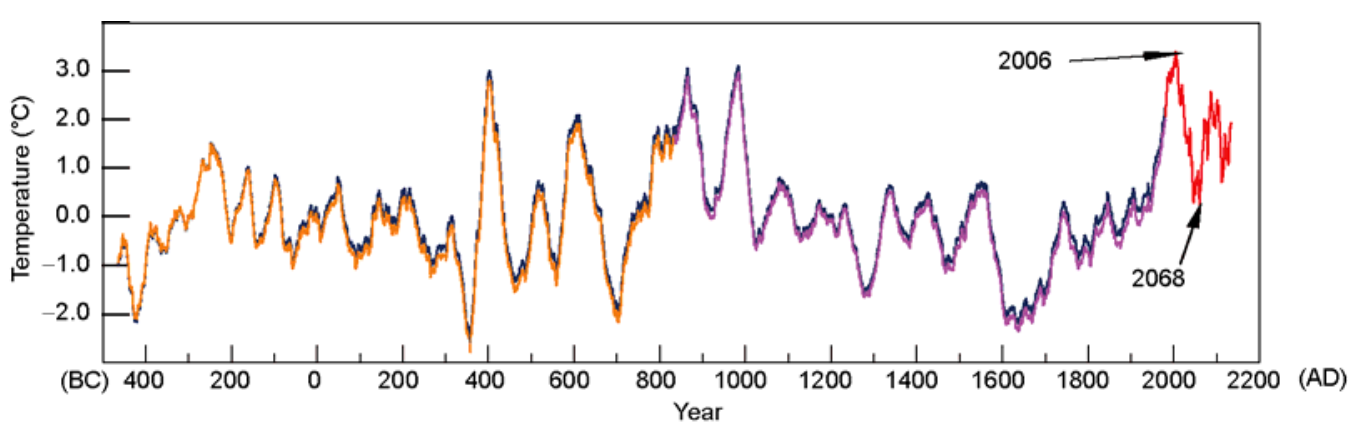

Figure 5 Prediction of temperature trends on the central-eastern Tibetan Plateau for the next 120 years. Blue line, initial series; orange line, calibration series, 464 BC-834 AD; purple line, verification series, 835-1980 AD; red line, forecasting series, 1980-2134 AD.

forecast the trends of precipitation variation in the Helan Mountains [18]. The prediction results have been partly verified with meteorological observations during the period without tree-ring data (1998-2009). The specific method has been detailed in reference [18].

The series of the 40 a moving average was used as the initial series, covering 2445 years (464 BC-1980 AD). The calibration period was from $464 \mathrm{BC}$ to $834 \mathrm{AD}$, the verification period was from $835 \mathrm{AD}$ to $1980 \mathrm{AD}$, the forecasting period was from $1981 \mathrm{AD}$ to $2134 \mathrm{AD}$, and verification during the observation period was from 1957 AD to 2006 $\mathrm{AD}$ (Figure 5). The observation data were average values for seven stations (Delingha, Dulan, Golmud, Lhasa, Nagqu, Dachaidan, and Bange) on the central-eastern Tibetan Plateau. Forecasting theory suggests that it is reliable to forecast for a period that is $10 \%$ of the initial series [17]. In this paper, the verification series was nearly 1200 years. It is thus feasible to forecast the temperature for the next 120 years. A recurrent method was employed and the mean- square error was made a minimum; in this work, the minimum mean-square error was 0.74 .

The prediction results show that the temperature continues to increase until $2006 \mathrm{AD}$ and then decreases to a minimum around $2068 \mathrm{AD}$. After $2068 \mathrm{AD}$, the temperature increases again until 2088 AD. This forecasting result differs from that of Qian et al. [60], who believed that the temperature would decrease until $2035 \mathrm{AD}$ and then increase again until 2068 AD.

The forecasted temperature series captured the trends of the observed data quite well (Figure 6), suggesting the reliability of the prediction.

\section{Conclusions}

This paper dealt with the amplitudes, rates, periodicities and causes of temperature variations on the basis of tree rings on the central-eastern Tibetan Plateau, and tentatively forecast the temperature trends for the next 120 years.

Climate events worldwide, such as the MWP and LIA, were seen in a 2485 -year temperature series. The largest

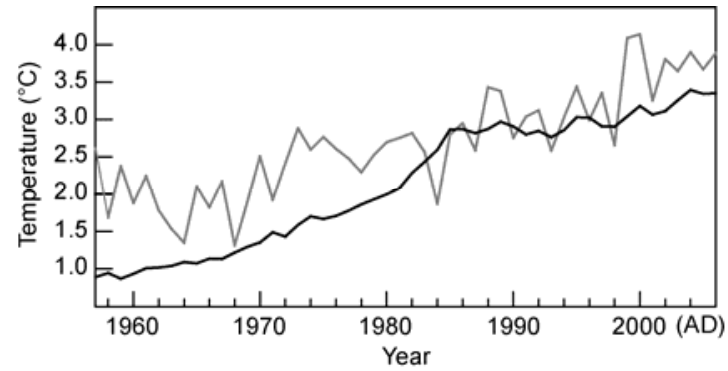

Figure 6 Temperature comparison between the forecast and observation data taken from seven stations on the central-eastern Tibetan Plateau (seven stations: Delingha, Dulan, Golmud, Lhasa, Nagqu, Dachaidan and Bange).

amplitude and rate of temperature both occurred during the EJE, but not in the late 20th century. The millennium-scale cycle of solar activity determined the long-term temperature variation trends, while century-scale cycles controlled the amplitudes of temperature. Sunspot minimum events were associated with cold periods.

The prediction results obtained using caterpillar-SSA showed that the temperature would increase until $2006 \mathrm{AD}$ on the central-eastern Plateau, and then decrease until 2068 $\mathrm{AD}$, and then increase again.

The regularity of 600-year temperature increases and 600-year decreases (Figure 3) suggest that the temperature will continue to increase for another 200 years, since it has only been about 400 years since the LIA. However, a decrease in temperature for a short period controlled by century-scale cycles cannot be excluded.

Obviously, solar activity has greatly affected temperature on the central-eastern Plateau. However, there are still uncertainties in our understanding of climate change, and the concentration of $\mathrm{CO}_{2}$ affects the climate. Further investigations are thus needed.

The authors thank Xu Xinguo, Tao Jianguo, Xin Feng and Li Te'er for their assistance. This work was supported by the National Natural Science Foundation of China (40890051), the Hundred Talents Program of the Chinese Academy of Sciences (KZCX2-YW-Q1-01), the Key Technology $R$ \& D Program of China (2007BAC30B01), and SKLLQG Foundation.

1 Hu F S, Kaufman D, Yongji S, et al. Cyclic variation and solar forcing of Holocene climate in the Alaskan subarctic. Science, 2003, 301: 
$1890-1893$

2 Ma L H. Thousand-year cycle signals in solar activity. Solar Phys, 2007, 245: 411-414

3 Bond G, Showers W, Cheseby M, et al. A pervasive millennium-scale cycle in North Atlantic Holocene and Glacial climates. Science, 1997, 278: 1257-1266

4 Dansgaard W, Johnsen H B, Clausen D, et al. North Atlantic climatic oscillations revealed by deep Greenland ice cores. Geophys Monogr, 1984, 29: 288-298

5 Shi Y F. Past 2000 years records and global change (in Chinese). Quat Sci, 1997, 17: 37-40

6 Yao T D, Duan K Q, Thompson L G, et al. Temperature variations over the past millennium on the Tibetan Plateau revealed by four ice cores. Ann Glaciol, 2007, 46: 362-366

7 Yu K F, Zhao J X, Shi Q, et al. U-series dating of dead Porites corals in the South China Sea: Evidence for episodic coral mortality over the past two centuries. Quat Geochronol, 2006, 1: 129-141

8 Tan M, Liu T S, Hou J Z, et al. Cyclic rapid warming on centennial-scale revealed by a 2650 -year stalagmite record of warm season temperature. Geophys Res Lett, 2003, 30: 1617-1620

9 Zhang P Z, Cheng H, Edwards R L, et al. A Test of climate, sun, and culture relationships from an 1810-year chinese cave record. Science, 2008, 322: 940-942

10 Xiao J L, Wu J T, Si B, et al. Holocene climate changes in the monsoon/arid transition reflected by carbon concentration in Daihai lake of Inner Mongolia. Holocene, 2006, 16: 551-560

11 Zhang D E, Li H C, Ku T L, et al. On linking climate to Chinese dynastic change: Spatial and temporal variations of monsoonal rain. Chinese Sci Bull, 2010, 55: 77-83

12 Zheng J Y, Wang W C, Ge Q S, et al. Precipitation variability and extreme events in eastern China during the past 1500 years. Terr Atmos Ocean Sci, 2006, 17: 579-592

13 Liu Y, An Z S, Hans W L, et al. Annual temperatures during the last 2485 years in the mid-eastern Tibetan Plateau inferred from tree rings. Sci China Ser D-Earth Sci, 2009, 52: 348-359

14 Cook E R, Esper J, D'Arrigo R D. Extra-tropical Northern Hemisphere land temperature variability over the past 1000 years. Quat Sci Rev, 2004, 23: 2063-2074

15 Liu Y. Temperature tele-connections reflected in tree rings and ice core from high-latitude regions between Northern and Southern Hemispheres (in Chinese). J Earth Environ, 2010, 2: 100-104

16 Schulz M, Mudelsee M. REDFIT. Estimating red-noise spectra directly from unevenly spaced paleoclimatic time series. Comp Geosci, 2002, 28: 421-426

17 Golyandina N, Nekrutkin V, Zhigljavsky A, et al. Analysis of time series structure. CHAPMAN \& HALL, CRC, Boca Raton London New York Washington, D C. 2001. 1-305

18 Liu Y, Shishov V, Shi J F, et al. The forecast of seasonal precipitation trend at the north Helan Mountain and Baiyinaobao regions, Inner Mongolia for the next 20 years. Chinese Sci Bull, 2004, 49: 410-415

19 Zhu K Z. A preliminary study on climate changes since the last 5000 years in China. Acta Archaeol Sin, 1972, (1): 168-189

20 Briffa K R. Annual climate variability in the Holocene: Interpreting the message of ancient trees. Quat Sci Rev, 2000, 19: 87-105

21 Esper J, Cook E R, Schweingruber F H. Low frequency signals in long tree-ring chronologies for reconstructing past temperature variability. Science, 2002, 295: 2250-2253

22 Moberg A, Sonechkin D M, Holmgren K, et al. Highly variable Northern Hemisphere temperatures reconstructed from low- and high-resolution proxy data. Nature, 2005, 433: 613-617

23 Qin D H, Chen Z L, L Y, et al. Updated understanding of climate change sciences. Adv Clim Change Res, 2007, 3: 63-73

24 Wang H C. The relationship between the migrating south of the nomadic nationalities in north China and the climatic changes. Sci Geogr Sin, 1996, 16: 274-279

25 Grootes P M, Stuiver M. Oxygen 18/16 variability in Greenland snow and ice with 10-3 to 105-year time resolution. J Geophys Res, 1997, 102: $26455-26470$

26 Mann M E. Little Ice Age. In: Munn T, ed. Encyclopedia of Global
Environmental Change. London: John Wiley and Sons Ltd, 2002. 504-509

27 Hong Y T, Liu D S, Jiang H B, et al. Evidence for solar forcing of climate variation from peat cellulose. Sci China Ser D-Earth Sci, 2000, 43: 217-224

28 Qian W H, Lu B, Zhu C W. How would global-mean temperature change in the 21st century? Chinese Sci Bull, 2010, 55: 1963-1967

29 Cook E R, Meko D M, Stockton C W. A new assessment of possible solar and lunar forcing of the bi-decadal drought rhythm in the western United States. J Clim, 1997, 10: 1343-1356

30 Baldwin M P, Gray L J, Dunkerton T J, et al. The quasi-biennial Oscillation. Rev Geophys, 2001, 39: 179-229

31 Liu Y, Ma L M, Cai Q F, et al. March to April mean temperature reconstruction from tree rings for Zhen'an region (in Chinese). Prog Nat Sci, 2001, 11: 157-162

32 Liu Y, Ma L M, Cai Q F, et al. Reconstruction of summer temperature (June-August) at Mt. Helan, China, from tree-ring stable carbon isotope values since AD 1890. Sci China Ser D-Earth Sci, 2002, 45: $1127-1136$

33 D'Arrigo R, Mashig E, Frank D, et al. Temperature variability over the past millennium inferred from Northwestern Alaska tree rings. Clim Dyn, 2005, 24: 227-236

34 Gou X H, Deng Y, Chen F H, et al. Tree ring based stream flow reconstruction for the Upper Yellow River over the past 1234 years. Chinese Sci Bull, 2010, 55: 4179-4186

35 Ding Y G, Yu J H, Shi N. Quasi-biennial oscillation variability in interannual variance of the global surface temperature during the last 100-year period. Chin J Atmos Sci, 2001, 25: 89-102

36 Raspopov O M, Dergachevb V A, Kolström T. Periodicity of climate conditions and solar variability derived from dendrochronological and other palaeo-climatic data in high latitudes. Palaeogeogr Palaeoclimatol Palaeoecol, 2004, 209: 127-139

37 Schlesinger M E, Ramankutty N. An oscillation in the global climate system of period 65-70 years. Nature, 1994, 367: 723-726

38 Kloosterboer-van Hoeve M L, Steenbrink J, Visscher H, et al. Millennial-scale climatic cycles in the early Pliocene pollen record of Ptolemais, northern Greece. Palaeogeogr Palaeoclimatol Palaeoecol, 2006, 229: 321-334

39 Chen F H, Wu H B, Zhang J W, et al. Study on the winter monsoon variations in Lanzhou area since the last deglaciation (in Chinese). Quat Sci, 1999, 4: 306-313

40 Isono D, Yamamoto M, Irino T, et al. The 1500-year climate oscillation in the midlatitude North Pacific during the Holocene. Geology, 2009, 37: 591-594

41 Sirocko F, Garbe-Schönberg D, Mclntyre A, et al. Teleconnection between the subtropic monsoons and high-latitude climates during the last Deglaciation. Science, 1996, 272: 526-529

$42 \mathrm{Xu} \mathrm{J} \mathrm{H}$. Sun, climate, famine and folk nation transfer (in Chinese). Sci China Ser D-Earth Sci, 1998, 28: 366-384

43 Zhou W J, Lu X F, Wu Z K, et al. Peat record reflecting Holocene climatic change in the Zoige Plateau and AMS radiocarbon dating. Chinese Sci Bull, 2002, 47: 66-70

44 Liu J Q, Lü H Y, Negendank J, et al. Periodicity of Holocene climatic variations in the Huguangyan Maar Lake. Chinese Sci Bull, 2000, 45: $1529-1532$

45 Braun H, Christl M, Rahmstorf S, et al. Possible solar origin of the 1470-year glacial climate cycle demonstrated in a coupled model. Nature, 2005, 438: 208-211

46 Eddy J A. Climate and the changing sun. Clim Change, 1977, 1: 173-190

47 Sonett C P, Finney S A, Berger A. The spectrum of radiocarbon. Phil Trans R Soc Lon, 1990, 330: 413-426

48 Damon P E, Sonnett C P. Solar and terrestial components of the atmospheric ${ }^{14} \mathrm{C}$ variation spectrum. In: Sonett $\mathrm{C} P$, ed. The Sun in Time. Tuson: Arizona Univ Press, 1991. 360-388

49 Wang L, Sarnthein M, Erlenkeuser H, et al. East Asian monsoon climate during the Late Pleisocene: High-resolution sediment records from the South China Sea. Mar Geol, 1999, 156: 245-284

50 Cook E R, Buckley B M, D'Arrigo, et al. Warm-season temperatures 
since $1600 \mathrm{BC}$ reconstructed from Tasmanian tree rings and their relationship to large-scale sea surface temperature anomalies. Clim Dyn, 2000, 16: 79-91

51 Hodell D A, Brenner M, Curtis J H, et al. Solar forcing of drought frequency in the Maya lowlands. Science, 2001, 292: 1367-1370

52 Neff U, Burns S J, Mangini A, et al. Strong coherence between solar variability and the monsoon in Oman between 9 and 6 kyr ago. Nature, 2001, 411: 290-293

53 Agnihotri R, Dutta K, Bhushan R, et al. Evidence for solar forcing on the Indian monsoon during the last millennium. Earth Planet Sci Lett, 2002, 198: 521-527

54 Fleitmann D, Burns S J, Mudelsee M, et al. Holocene forcing of the Indian monsoon recorded in a stalagmite from Southern Oman. Science, 2003, 300: 1737-1739

55 Zhong W, Wang L G, Tyip T, et al. Possible solar forcing of climate variability in the past 4000 years inferred from a proxy record at the southern margin of Tarim Basin. Chinese Sci Bull, 2004, 49: 11901195

56 Delmonte B, Petit J R, Krinner G, et al. Ice core evidence for secular variability and 2002 year dipolar oscillations in atmospheric circulation over East Antarctica during the Holocene. Clim Dyn, 2005, 24: 641-654

$57 \mathrm{Xu} \mathrm{H}$, Hong $\mathrm{Y} \mathrm{T}$, Lin $\mathrm{Q} \mathrm{H}$, et al. Temperature responses to quasi100 -year solar variability during the past 6000 years based on $\delta^{18} \mathrm{O}$ of peat cellulose in Hongyuan, eastern Qinghai-Tibet Plateau, China. Palaeogeogr Palaeoclimatol Palaeoecol, 2006, 230: 155-164

58 Raspopov O M, Dergachev V A, Esper J, et al. The influence of the de Vries ( 200-year) solar cycle on climate variations: Results from the central Asian Mountains and their global link. Palaeogeorg Palaeoclimatol Palaeoecol, 2008, 259: 6-16

59 Ogurtsov M, Sonninen E, Hilasvuori E, et al. Variations in tree ring stable isotope records from northern Finland and their possible connection to solar activity. J Atmos Sol-Terr Phy, 2010, 73: 383-387

60 Qian W H, Lu B. Periodic oscillations in millennial global-mean temperature and their causes. Chinese Sci Bull, 2010, 55: 4052-4057

61 Usoskin I G, Solanki S K, Schüssler M, et al. Millennium-scale sunspot number reconstruction: Evidence for an unusually active sun since the 1940s. Phys Rev Lett, 2003, doi: 10.1103/physRevLett.91.211101

Open Access This article is distributed under the terms of the Creative Commons Attribution License which permits any use, distribution, and reproduction in any medium, provided the original author(s) and source are credited. 